\title{
Dynamic modelling of reconfigurable manufacturing planning and control systems using supervisory control
}

\author{
Ahmed M. Deif and Waguih H. ElMaraghy* \\ Department of Industrial and Manufacturing Systems Engineering, \\ Intelligent Manufacturing Systems Research Centre (IMS), \\ University of Windsor, \\ ON, Canada \\ E-mail: wem@uwindsor.ca \\ E-mail: Ahmed.Deif@uregina.ca \\ ${ }^{*}$ Corresponding author
}

\begin{abstract}
This research is concerned with studying the dynamic performance of reconfigurable Manufacturing Planning and Control (MPC) systems. Such goal requires two main tasks. The first task is to develop a dynamic MPC system model that has the ability to reconfigure to different MPC policies. The second task is to design a supervisory control unit that has as input the high level strategic market decisions and constraints together with a leedback of the current manufacturing system state and then select the optimal suitable operation mode or policy at these conditions. This paper addresses the first task of the proposed research and presents and analyses a dynamic reconfigurable MPC model. The response of the developed model to sudden demand changes under different parameters settings is analysed. In addition, the stability limits of the system are also studied. The results give a better understanding of the dynamics of reconfigurable MPC systems and the different trade-off decisions required when selecting an MPC policy and the limits for parameters settings. These results represent the first step towards designing the supervisory control unit which will be responsible for managing the reconfiguration of the whole system.
\end{abstract}

Keywords: dynamic modelling; reconfigurable planning and control.

Reference to this paper should be made as follows: Deif, A.M. and EMaraghy, W.H. (2009) 'Dynamic modelling of reconfigurable manufacturing planning and control systems using supervisory control', Int. J. Manufacturing Technology and Management, Vol. 17, Nos. 1/2, pp.82-102.

Biographical notes: Ahmed M. Deif is presently an Assistant Professor at University of Regina, Saskatchewan, Canada. He earned his $\mathrm{PhD}$ from the Department of Industrial and Manufacturing Systems at the University of Windsor in 2006. He received his MASc from the same department in 2003 and his BSc from The American University in Cairo in 1999. His research interests are in manufacturing capacity management, and dynamic analysis of manufacluring systems and RMS.

Waguih H. ElMaraghy is a Professor of Engineering and the Director of the Intelligent Manufacturing Systems (IMS) Centre, Department of the Industrial and Manufacturing Systems Engineering, University of Windsor. He is also a Senior Member of the Society of Manufacturing Engineers (SME), the Society 
of Automotive Engineers (SAE), a Fellow of the Canadian Society for Mechanical Engineering (CSME), a Fellow of the American Society of Mechanical Engineers (ASME) and a Member of the CIRP Academy). He is an Active Researcher and author wilh expertise in engineering design, manufacturing automation and industrial productivity.

\section{Introduction}

Reconfigurable Manufacturing System (RMS) is a new class of manufacturing systems proposed recently, which aims at combining the high throughput of Dedicated Manufacturing Lines (DML) with the flexibility of Flexible Manufacturing Systems (FMS) (Koren et al., 1999). This could be achieved through the fast scaling of capacity and functionality, in response to new circumstances, by rearrangement or change of its components (Mehrabi et al., 2000). In other words, this new paradigm calls upon the continuous adaptation of the manufacturing system to cope with the turbulent and uncertain market demands. Amongst a number of subsystems of manufacturing, the Manufacturing Planning and Control (MPC) system is recognised as one of the pivotal infrastructures that firmly supports the organisation's manufacturing to align with its higher lcvel market strategy (Wacker and Hanson, 1997). Thus, the evolution of RMS requires a parallel one to the classical MPC systems to support RMS in the modern market environment.

Many researchers think that the classical MPC strategies such as the push strategy can never be adopted in RMS paradigm. However, RMS is designed to adopt any manufacturing strategy as long as it will maintain the required marketing objectives. Therefore, a reconfigurable MPC system should have the ability to adapt to the organisation current market strategy, whether it was a push, pull or any other kind of strategy that the organisation follow at a certain period based on the current market trend of that period. Chan and Burns (2002) showed that the general consensus based on various comparative studies is that the existing MPC systems complement each other rather than being competitive. There is no single perfect MPC strategy suited for all types of manufacturing condilions and marketing trends.

The MPC systems are diverse and extensive, however, from an operational standpoint they can be defined as the functioning or operating modes of the manufacturing system that ensure meeting the market demand. Traditionally, they were catcgorised into two main calegories, push and pull systems (sometimes referred to as level scheduling and chase strategies). where each has its various enabling tools (Venkatesh ct al., 1996). The development of new technology such as modular design and open control architecture and the evolution of modern RMS gave the previous two general MPC systems new dimensions. One can perceive the push and pull MPC systems in today's modern manufacturing context as inventory based MPC system and capacity-based MPC system, respectively. Reconfigurable MPC system can operate in capacity based modes to be responsive and cost effective when mass customisation is the marketing competilive stralegy and in the case of variety of products with short life cycle. It can also operate in inventory-based modes in cases where market is stable for a long period or the demand forecast is of high degree of certainty or if the organisation is currently focusing on cost as the only market competitive stratcgy or if the customer 
service level is based on the availability of the products at any time. In addition, a mix between different modes is sometimes required (hybrid mode) as in the case of seasonal products. Thus, MPC systems in RMS will be subject to continuous reconfiguration over time in response to changing demand environments.

Studying such reconfigurable MPC system capability requires two main tasks. The first task is to develop a dynamic MPC system model that can reconfigure to different manufacturing modes. Traditional static views of MPC systems cannot reflect the rcconfigurability requirements of flexibility and fast adaptability to changing manufacturing strategics and thus a dynamic representation of the system where closed loops rather than open loops strategies are adopted is more realistic for this target. The dynamic model should express the system major parameters as Work In Progress (WIP), inventory and capacity levels as bcing dynamic and adaptable. The second task is to design a supervisory control unit that intakes the high level strategic market decisions and constraints together with a feedback of the current manufacturing system state and optimally reconfigures the MPC system to the optimal suitable operation mode at these conditions. This control unit should also be responsible for reacting to all unpredicted internal disturbances (such as breakdowns and other system variability parameters) and external disturbances (such as rush orders, change in product mix, etc.) in the same optimal way. This paper describes and analyses a dynamic model for reconfigurable MPC system and in an extension of this research work a supervisory controller will be designed to be responsible for the second task mentioned.

\section{Litcrature review}

Dynamic modelling of manufacturing systems attempts to capture and describe the behaviour of the system as they evolve over time under different operating conditions. This is why dynamic models are more appropriate in describing RMS as they are characterised by continuous internal and external disturbances as well as their capability to have different system configurations during their life cycle. Modern research of dynamic manufacturing systems applied different dynamical approaches to model and analyse these systems. The most popular dynamic modelling approach is the system dynamics SD approach with its various modelling tools initiated by Forrester in 1961. An extensive survcy about SD can be found in Baines and Harrison (1999) and manufacturing application examples can be found in Helo (2000), Reid and Koljonen (1999) and Wikner (1991). Other approaches to understand the dynamic naturc of manufacturing systems were through the application non-linear dynamic analysis (Radons and Neugebauer, 2005; Sholtz-Reiter and Shmieder, 2002; Wiendahl and Worbs, 2003) and chaos theory (Chryssolouris, 2004; Schmitz et al., 2002). One of the very successful dynamic attempts to model manufacturing systems was through the application control theoretic approaches. Some researchers consider this approach as part of the SD approach and others place the control approach as an independent dynamic approach due to its distinctive tools in terms of modelling and analysis.

The first approach to apply control theory to MPC systems was by Simon in 1952 . Recently, the potential for applying control theoretic approaches to model modern MPC systems have been initiated by Towill (1982) and since then it has been widely recognised. The review in this section is limited to examples of applying the feedback closed loop control techniques to modern MPC systems. Among the significant research 
studies of adopting this control approach was the research done to use the Automatic Pipeline, Inventory and Order Based Production Control Systcm (APIOBPCS) model developed by John et al. (1994) together with different feedback control theory tools to various manufacturing applications. Examples include the application to supply chain management as in Diseny and Towill (2002) and Towill and Del Vecchio (1994), inventory control as in Towill et al. (1997) and aggregate planning as in Dejonckheere et al. (2003). The funnel model of manufacturing systems developed by Wiendahl (1995) is another model that has been manipulated by feedback control approach with the help of logistic operating curves developed by Nyhuis (1994) to control WIP (Lodding et al., 2003) and WIP with backlog of manufacturing systems (Wiendahl and Breithaupt, 1999, 2000). A model devcloped by Duffie and Falu (2002) for closed loop PPC was used to control WIP and backlog of a single workstation in discrete and continues time domains in Ratering and Duffie (2003) and Kim and Duffie (2004) and respectively. Kim and Duffie (2005) extended that work to multiple work station model. Closed loop techniques were also applied to control arrival time (Duffie et al., 2002), capacity scalability in RMS (Asl and Ulsoy, 2002; Deif and ElMaraghy, 2006) and inventory in single and double stage manufacturing systems (Fong et al., 2004).

Based on the previous review one can realise two needs in modelling reconfigurable MPC systems. Firstly, the previous approaches dealt exclusively with events occurring on the shop-floor and how to control them, thus to maintain the market competitiveness of RMS to supply capacity and functionality when needed and where needed, there is a need to link this operational level with the high enterprise level (which is responsible for strategic decisions and dealing with market turbulence) in a seamless way. Such a link will close the loop of the whole enterprise making it more responsive and adaptable to changes. Secondly, it is shown that the main manufacturing system's parameters that manage the MPC operating configurations are the WIP level, the inventory level and the capacity level. All other parameters arc related to these parameters. No existing dynamic model, to the authors' knowledge, explicitly combines the three MPC parameters in an independent manner. Integrating these MPC parameters will enable the enterprise to switch between inventory-based and capacity-based MPC policies as a function of the market needs in an independent or hybrid fashion. To address the above needs, this paper proposes a reconfigurable MPC model that combines WIP, inventory and capacity and at the same time it is amenable to control theoretic analysis and synthesis techniques. Also a supervisory controller is introduced as a decision unit that carry out the task of linking the high enterprise marketing strategy with the manufacturing systems and its MPC stratcgy. This is achieved by designing a reconfiguration scheme to optimally reconfigure, based on the high level strategy and shop floor data, to the optimal MPC policy for the manufacturing systems.

\section{Reconfigurable MPC system model}

The dynamic modelling of the reconfigurable MPC systems aims at constructing a model in which different planning and control configurations can be realised with respect to a higher level adopted strategy. The modelling approach and its analysis arc based on the application of control theory and feedback analysis where continuous time domain is implemented to model the system states. 
The system shown in Figurc 1 is composed of the three main parameters that work individually or two of them can work simultaneously together based on the decision of the supervisory controller (the decision logic unit) to determine the Desired Production Rate (DPR). The parameters are the work in process WIP, the capacity rate of the system and the finished inventory level.

Figure 1 Reconfigurable MPC system model

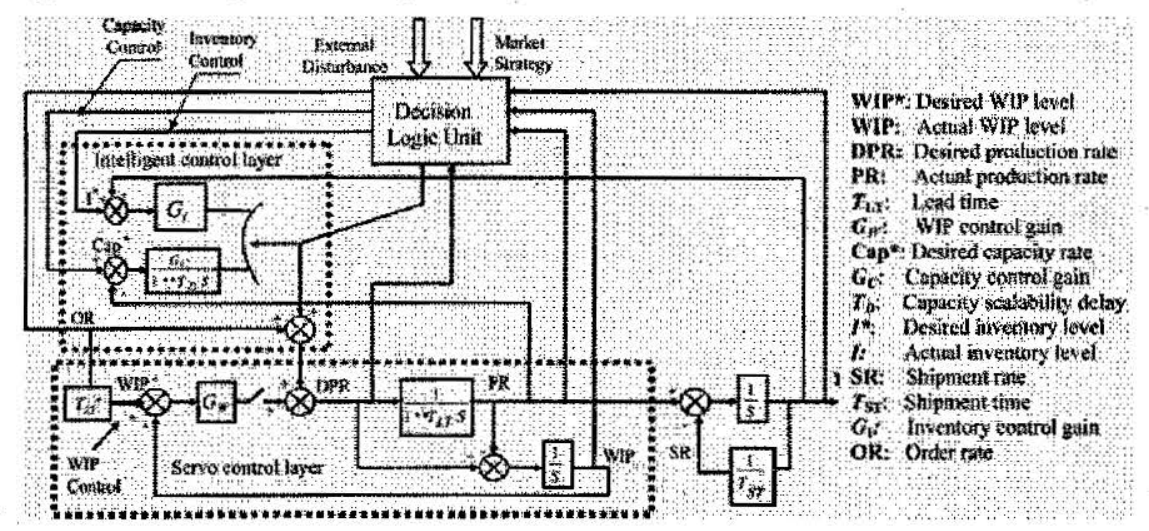

The general structure of the reconfigurable MPC system proposed can be expressed in words as being composed of two main operational layers plus a decision logic unit that links these two layers with the higher corporation management layer. The first operation layer is the default (or servo control layer) where the control of the manufacturing system is only based on controlling the WIP level. The other layer (intelligent control layer) involves two controllers, an inventory controller and a capacity rate controller. The engagement of either controller to the servo control layer or to work by itself, creating different MPC configuration or policies, is the responsibility of the decision logic unit (supervisory controller) as discussed previously. Also the decision logic unit provides the system with the reference control points and the updates of the Order Rate (OR) and shipment time based on demand data from the higher management level and at the same time collects all the data of the current system to help in deciding for the optimal MPC configuration or policy.

The production process is modelled as a pipeline where the outflow is simply lagged by the production lcad time, TLT (Sterman, 2000). Determining the exact value of pipeline lead time is a complex task (Hoyt, 1980) and is beyond the scope of this paper. However, exponential lag model is used in the developed model which can be considered representative of batch manufacture (Towill, 1982). Simulation results of such assumption showed exponential pipcline lag to be appropriate compromise between complexity and accuracy (Wikner et al., 1991).

\subsection{WIP-based MPC system}

This configuration is the default configuration in the reconfigurable MPC system. The WIP controller is engaged while the other two controllers are disconnected. WIP is an important control parameter as it ties up capital and costs interest (Lodding et al., 2003) 
and has direct relation with the production rate and production lead time. As mentioned bcfore production lead time is difficult to measure while WIP is casy to measure and therefore, WIP can be and indicative and easy parameter to use for normal control of manufacturing system.

This MPC system configuration observes the WIP level and compares it to a reference WIP level. Based on the crror between the two levels the WIP controller adjusts the WIP level through a gain $\left(G_{w}\right)$ and adds this amount together with the OR to the DPR level. WIP level is calculated as the difference bctween the DPR and the actual Production Rate (PR) and the latter is due to an exponential time delay of the DPR based on the system's production lead time $T_{\mathrm{Lr}}$ (John et al., 1994).

The desired WIP level is calculated as a product of multiplying the OR with the estimated (ideal) lead time of the production system $T_{\mathrm{LT}}^{*}$ as indicated by Little's law. The control gain $\left(G_{w}\right)$ can be physically described as increasing or decreasing the input rate of work to the production system since stocks, as in case of WIP, are altered only by changes in their inflow and outflow rates.

\subsection{Capacity-based MPC system}

This configuration is achieved by only engaging the capacity controller into the system. Capacity controller is very important in the cases when there is a highly varying input of orders caused by prefabrication or a frequently changing order situation (Pritschow and Wiendah1, 1995). This configuration also suits the typical RMS case where exact capacity is needed and it should match demand without any backlog. Idcally this configuration suits the make to order MPC strategy. Today's modern technology based on modularity and open architecture control enabled RMS to adjust their capacity much easier.

This MPC system configuration observes the PR and compares it to a reference capacity rate. Based on the error between the two rates the capacity controller adjusts the capacity rate through a gain $\left(G_{c}\right)$ and adds this amount to the DPR level. The reference capacity rate in this configuration is set to be equal to the OR and given through the decision logic unit. Sudden rush orders or any demand disturbance will immediately be reflected on the value of Cap".

The capacity scalability delay time, $T_{D}$, is important to considcr when capacity scalability controllers are involved and usually used to measure the degree of reconfigurability of the manufacturing system. Examples of the control gain $\left(G_{c}\right)$ are adding or removing machines, adding or removing machine tools or components and increasing or decreasing working shifts (ElMaraghy, 2003).

\subsection{Finished inventory based MPC system}

The 3rd configuration of the reconfigurable MPC model is based on controlling the finished inventory level only. This is achieved by cngaging the inventory controller and disconnecting other controllers. One of the principle reasons uscd to justify investments in finished inventory is its role as a buffer to absorb demand variability (Baganha and Cohen, 1998). In other words, finished good inventory is usually important for corporation which locates its market competitiveness position based on the high customer service level. Example of this case is the medical supplies market (Towill 
et al., 1997). This configuration is typically suitable for companies adopting a push marketing strategy and a make to stock policy where the fill rate is the major performance measure of the manufacturing system.

This configuration observes the finished inventory level I and compares it to a reference finished inventory level $I^{*}$. Based on the error between the two levels the inventory controller adjusts the inventory level through a gain $\left(G_{1}\right)$ and adds this amount together with the OR to the DPR level.

The Shipment Rate (SR) is calculated through dividing the previous finished inventory level by average shipment time and the later is determined by the higher management level based on the market strategy and shipments data. The control gain $\left(G_{\mathrm{I}}\right)$ can be physically described as increasing or decreasing the input rate to the system.

\subsection{Capacity and WIP based MPC system}

The 4th configuration of the reconfigurable MPC model is based on controlling both the WIP level and the capacity rate. This is achieved by engaging the WIP controller together with capacity rate controllcr. Accounting for WIP is very important as it decreases the oscillation of the system. However, in reality any manufacturing system configuration has a WIP increase limit which is the upper capacity limit of that system's configuration (Hopp and Spearman, 1996). To overcome this problem and keeping the advantage of having a WIP based MPC system, the system's capacity should be (scaled). This is achieved through a capacity rate controller.

The WIP controller is appropriate for the normal production control beyond the max WIP point. If the lead time keeps growing due to any internal disturbances or if there is a rush order, the queue of waiting orders in front of the system (WIP level) can be diminished by decreasing the system's input rate through the WIP controller. However, if there is a due date limit (which is a typical case in RMS) then the input rate can be reduced. The capacity rate controller only functions when the maximum WIP level of the system is reached and the input rate cannot be decreased, as otherwise backlog does not arise. This point is indicated by the decision logic unit based on the current system's configuration limitation and the required utilisation level.

However, if the capacity is increased to compensate for the undesirable WIP increase and then the system is back into the default WIP controller, the system can be in a state of unutilised capacity. The WIP controller will not detect this problem. Thus the capacity controller will also be used to resolve this undesired situation by obscrving the PR and comparing it to a capacity reference point. The automatic synchronisation between the two controllers is the decision logic unit's job.

\subsection{Finished inventory and WIP based MPC system}

The 5th configuration is based on controlling both the WIP level and the inventory level. This is achieved by engaging the WIP controller together with finished inventory level controller. This structure is usually used to have an optimal trade-off balance between inventory cost and production adaptation cost when considering the whole supply chain.

If a perfectly levelled production rate is used via the WIP controller then large inventory deviations are found and thus increasing the inventory cost or decreasing the service lcvel. Conversely, if inventory deviations are minimised using the inventory controller then high production variation (especially in terms of scheduling) will be 
realised leading to higher production cost. This trade-off problem has been illustrated using control theory by Vassian (1955), Deziel and Elion (1967), Towill (1982) and Towill et al. (2003).

\subsection{Mathematical model for developed reconfigurable MPC system's configurations}

Equations (1)-(5) list the transfer functions for the developed reconfigurable MPC system configurations. Without losing the generality, two basic assumptions were made. Firstly, the expected lead time is assumed to be equal to the actual one $\left(T_{1 T}=T_{2 T}{ }^{\circ}\right.$ ). Secondly, the $S R$ is set to be equal to the $O R(S R=O R)$. These assumptions are made only for better understanding the problem and the proposed model does not have any limitations considering the case of any linear or non-linear relation between these variables. Relaxation of these assumptions is conducted in further research.

WIP-based MPC system

$$
\frac{\mathrm{WIP}}{\mathrm{WIP}^{*}}=\frac{\left(G_{W}+T_{\mathrm{LT}}^{-1}\right)}{S+\left(G_{W}+T_{\mathrm{LT}}^{-1}\right)}
$$

Capacity-based MPC system

$$
\frac{\mathrm{PR}}{\mathrm{Cap}^{*}}=\frac{G_{C} T_{\mathrm{LI}}^{-1} T_{D}^{-1}}{S^{2}+S\left(T_{\mathrm{LT}}^{-1}+T_{D}^{-1}\right)+\left(1+G_{C}\right) T_{\mathrm{LT}}^{-1} T_{D}^{-1}}
$$

Finished inventory-based MPC system

$$
\frac{I}{I^{*}}=\frac{G, T_{\mathrm{LT}}^{-1}}{S^{2}+S\left(T_{\mathrm{LT}}^{-1}+T_{\mathrm{SK}}^{-1}\right)+G, T_{\mathrm{LT}}^{-1}}
$$

Capacity and WIP-based MPC system

$$
\frac{\mathrm{PR}}{\mathrm{Cap}^{*}}=\frac{G_{W}\left(T_{\mathrm{LT}}^{-1}+S\right)+G_{C} T_{\mathrm{LT}}^{-1} T_{D}^{-1}}{S^{2}+S\left(T_{D}^{-1}+T_{\mathrm{LT}}^{-1}+G_{W}\right)+\left(G_{W} T_{\mathrm{LT}}+G_{C}+1\right) T_{\mathrm{LT}}^{-1} T_{D}^{-1}}
$$

Finished inventory and WIP-based MPC system

$$
\frac{I}{I^{*}}=\frac{G_{I} T_{\mathrm{LT}}^{-1}}{S^{2}+S\left(G_{w}+T_{\mathrm{LT}}^{-1}+T_{\mathrm{SR}}^{-1}\right)+\left(G, T_{\mathrm{LT}}^{-1}\right)}
$$

\subsection{The decision logic unit}

Figure 2 shows the architecture of the DLU in the proposed model. The architecture of the DLU is composed of three hierarchal layers and thus it is a multilayer unit. The first two layers function offline and the third layer is an online control layer.

The first layer or unit is called MPC policy selection unit. This unit is responsible for analysing the anticipated demand profile by the higher management level. Based on the analysis of the demand profile, the unit decides on which policy (or MPC configuration) to be adopted over which interval of time of that expected demand. In other words, the output would be a plan that indicates which MPC policy (inventory/WIP, capacity/WIP or inventory) to be applied during which months of the year (if the demand profile was 
anticipated monthly). It is important to note that this unit can deal with sudden changes in the anticipated demand. Such ability is very important in agile manufacturing environments.

Figure 2 Architecture of the DLU in the reconfigurable MPC model (see online version for colours)

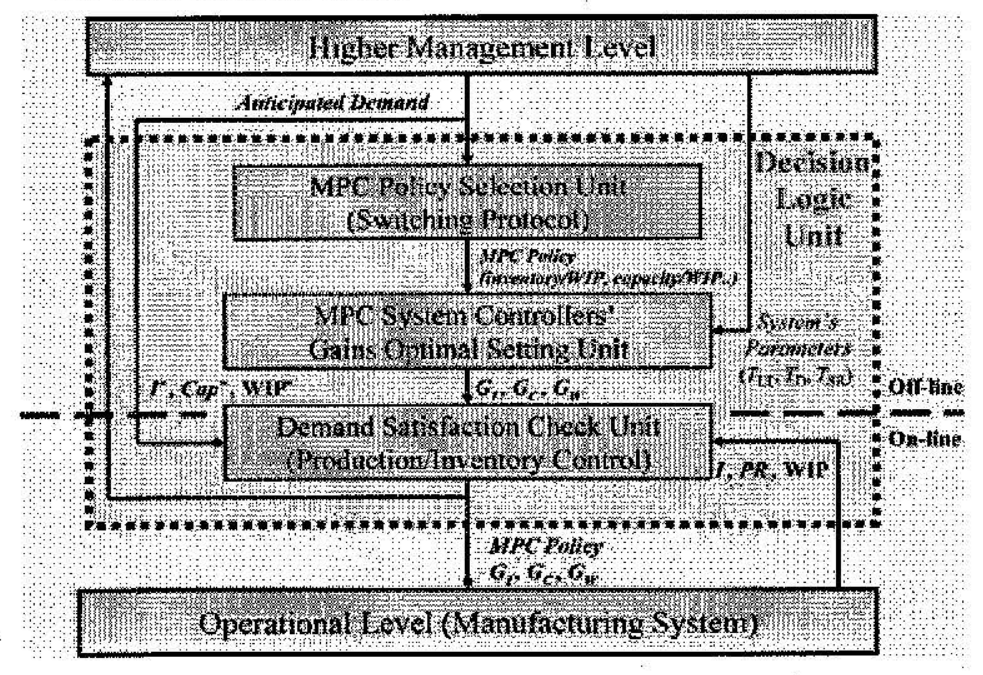

From a control perspective, this selection process can be considered the switching protocol that governs the engagement and disengagement of the different controllers involved in the developed agile MPC system.

The second layer is called MPC system controllers' gains optimal setting unit. This can be considered the heart of the developed DLU. This unit is responsible for deciding on the optimal values of the different controllers' gains in the developed agile MPC system. By optimal, we mean the value of the gains that will satisfy the competing RMS objectives of responsiveness and cost effectiveness.

This unit receives from the previous unit the plan with the selected MPC policies and based on each policy (or configuration) it calls the model (or the transfer function derived in the previous section) of that configuration and manipulate it in the optimisation process. The output of that unit is the optimal controllers' gain for each configuration based on the given manufacturing system's parameters.

The last layer is called MPC demand satisfaction check unit. This layer is actually responsible for checking that the current production or inventory level satisfies the required demand and this is why it takes place online. The check is based on comparing the current production level with the required capacity rate, the current WIP level with the ideal WIP level and the current inventory level with the target inventory level (depending on which MPC policy is being adopted). These reference levels are actually calculated based on the anticipated demand and thus meeting these levels means satisfying the market demand.

Based on the discrepancy between the compared levels, a decision is made to compensate for that discrepancy through the previously calculated optimal control gains values. This process is carried out in an interactive basis with the operational level that is 
the manufacturing system updates this unit in the DLU with the current status of the system and based on the previously fed data of the demand, a control action is decided. Thus this unit is mainly responsible for what is known in the literature of MPC systems as production control.

\section{Reconfigurable MPC system model analysis}

The objectives of this analysis are to examine the dynamic characteristics of the model and also to see the effect of the different controllers' gains on these characteristics. These effects will help in designing the MPC system and will act as a reference for the supervisory controller or the DLU when selecting the best MPC system configuration and its control settings. The parametric analysis of the other time variables such as the lead time, shipment time and delay time are conducted in a further research. In this research they are assumed to be constant.

\subsection{Response analysis}

As is customary a deterministic step input is used to evaluate the system ability to cope with a sudden change in demand since this is a repeated scenario in RMS environment. The response in a step change in demand is of importance not only because it gives a shock to the system but additionally it is an input that is easily visualised and interpreted. It also determincs the basic dynamic characteristics of the system (Coyle, 1996). Figure 3 compares between the responses of the different MPC system configuration to a step change in demand with the given parameters selting.

The analysis of the MPC response to this step change reveals three main observations.

Figure 3 Response of the different MPC configurations for a step change in demand ( $T_{\mathrm{Lr}}=5$ days, $T_{D}=3$ days, $T_{\mathrm{sR}}=3$ days, $G_{w}=1, G_{f}=1$ and $G_{c}=7$ ) (see online version for colours)

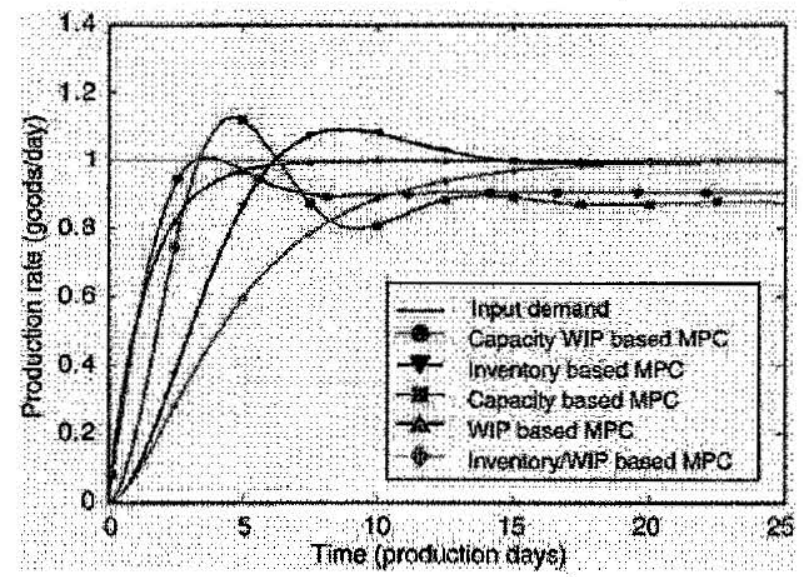


Firstly, the initial response to demand sudden change is a production overshoot in all configurations except the default configuration (the WIP-based MPC system). The overshoot in the WIP/Inventory-based MPC system is not clearly seen due to the over-damping of the system with this value of the WIP gain $\left(G_{w}\right)$. This is more cxplained later. This overshooting characteristic is very important when considering the level of the stability and cost a firm would like to have for its production. This overshoot in production can be explained based on the MPC policy adopted. In the capacity based configurations (with or without WIP compensation), this overshoot reflects the increase of production level to chase the demand since this is the market objective of that policy. In the inventory based configurations (with or without WIP compensation), this overshoot reflects the desire to compensate for the loss in the inventory level due to this demand change and keeping the target service level since this is the market philosophy of that policy.

Secondly, the rise time (the time it takes the system to rise from $10 \%$ to $90 \%$ of its target value) for the capacity-based MPC configurations is much less than that for the inventory-based MPC configurations indicating more responsiveness in adopting the first policy. This can be explained since in the capacity based policies, the production directly follow the demand (exact capacity when needed and where needed). However, in the inventory-based policies, the production first has to fill the inventory gap due to the demand change and then match the demand level which leads to a sort of phase lag that is reflected in the rise time. The rise time, together with other response time parameters like settling time and time constant, can be used to evaluate the agility of the system in response to fluctuating demand from a dynamical stand point.

Finally, there is a production offset in the capacity-based MPC policies. This violates one of the fundamentals of RMS which is supplying exact capacity when needed. Solution for this problem will be explained later in this paper.

\subsubsection{The effect of the inventory controller gain}

As mentioned earlier it is important to examine the effect of different controllers to guide the supervisory controller to the optimal settings of the MPC parameters. The first controller to be examined is the inventory controller which contributes to the system by increasing or decreasing the input rate. Figure 4(a) and (b) shows the effect of different valucs of the inventory controller gain when the MPC system (whether it is inventory or inventory/WIP-based) is subjected to a step change in demand.

Analysis of the results shows that there are various compcting objectives that need trade-off decisions (which are one of the tasks the supervisory controller based on the higher level market strategy). An insight about these trades-offs is as follows:

Firstly, in both MPC policies, as the inventory control gain increases, the system is more responsive. However, this is on the expense of having a production level overshoot which conforms to what was stated earlier in tcrms of the trade-olf between decreasing cost of production and maintaining an acceptable customer service level. The production overshoot from a manufacturing point of view was explained earlier as the response of the system to compensatc for the inventory level fall and reach the new demand level. From a dynamic analysis stand point, this can be also related to the structure of the MPC system model. The adjustment of inventory is actually a stock flow problem and thus there will always be amplification (overshoot) in the stock adjustment process. The only way for this structure to respond to changes is by having the production excceds the 
demand change which means that the overshoot is inevitable. However, this amplification is related to the demand change in what is known as the amplification ratio which is the peak of the production overshoot divided by the demand change. This ratio depends on the adjustment time of MPC system and at the same time reflects production cost. Thus the trade-off decision that should be taken by the supervisory controller is to decide on the amount of the controller gain value within the accepted amplification ratio set by the high level management and the required responsiveness level.

Secondly, at the same value of the inventory controller gain, the inventory-based MPC policy has a lower rise time than inventory/WIP-based MPC policy indicating more responsiveness. This is because in the later policy the production rate has to compensate for the required WIP level before matching the demand and thus takes longer time. However, the overshoot is less when WIP compensation is included due to its damping effect. Also the settling time of the inventory/WIP-based MPC policy is longer than the inventory-based one. Thus the same competing objectives (responsiveness versus reducing amplification or production cost) will also guide the decision of the supervisory controller whether or not to compensate for WIP when adopting inventory MPC policy.

Figure 4 Response of a) inventory-based MPC configuration b) the inventory/WIP-based MPC configuration for a step change in demand with different inventory gain values ( $T_{\mathrm{LT}}=5$ days, $T_{\mathrm{sR}}=3$ days and $G_{\mathrm{w}}=0.25$ ) (see online version for colours)
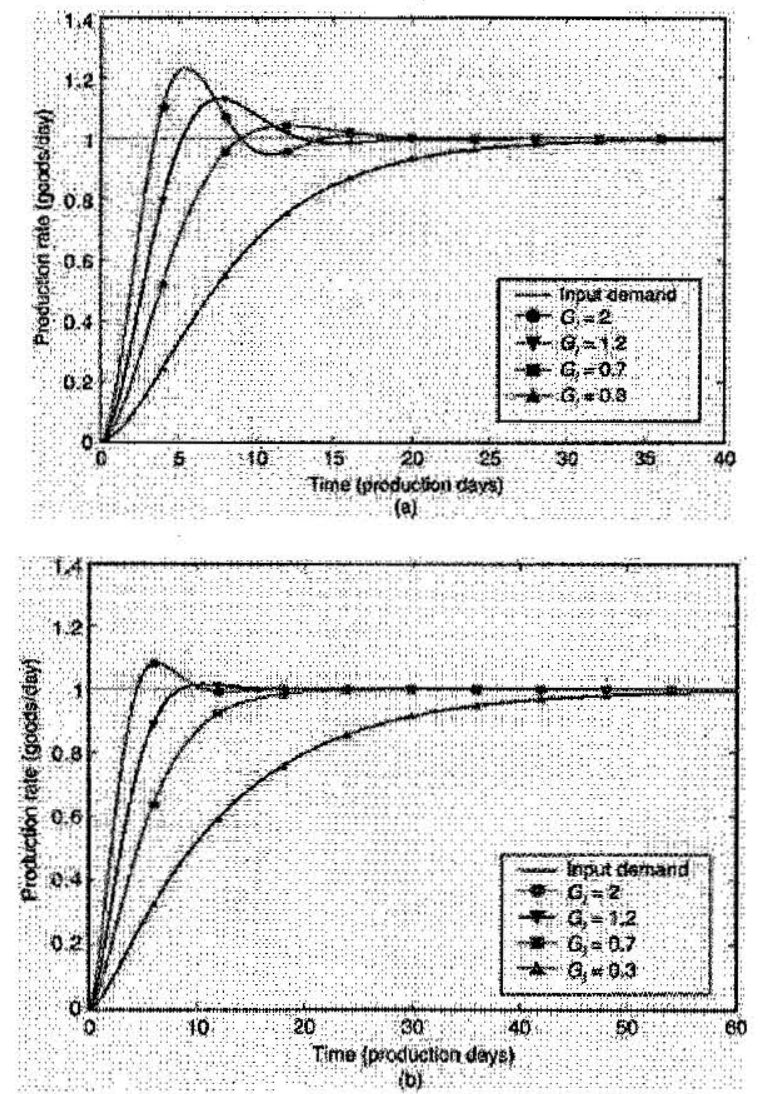


\subsubsection{The effect of the capacity controller gain}

The value of the capacity gain controller is varied and the response of both capacity-based MPC systems against a step change in demand is tested. The results for both systems are shown in Figure 5 (a) and (b). Analysing the results points to the following observations.

Figure 5 Response of (a) the capacity-based MPC and (b) the capacity-based MPC configurations for a step change in demand with different capacity gain valucs ( $T_{\mathrm{LT}}=5$ days and $T_{D}=3$ days and $G_{\mathrm{w}}=0.25$ ) (see online version for colours)
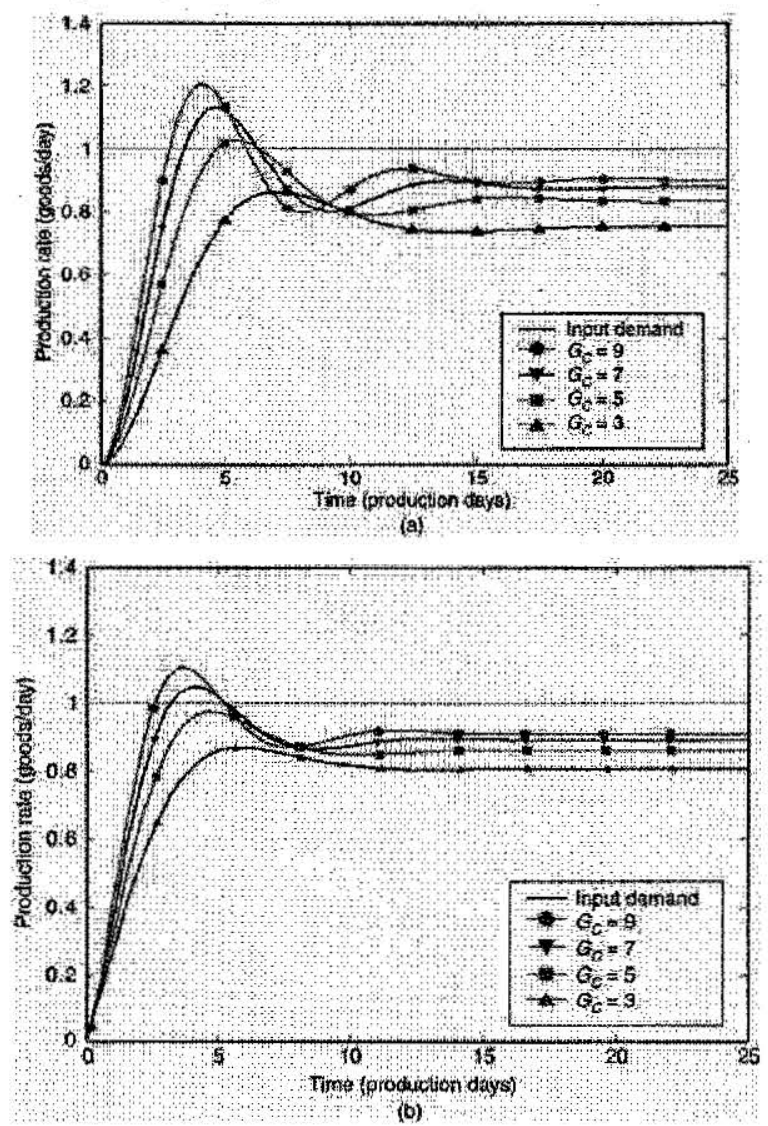

Firstly, in both capacity-based MPC policies, no matter how much the capacity controller gain is increased, there will always be a production offset. This problem violates one of the main objectives of implementing RMS which is supplying exact capacity to match the demand. The solution for this problem is through redesigning the capacity controller to include together with proportional component an integral parameter to account for all soft and hard activities associated with scaling the capacity and thus eliminating this offset. Details of these activities and the new design of the capacity controller were published in Deif and ElMaraghy (2006). 
Secondly, as the controller gain increases, the production offset decreases. This is obvious since this gain actually compensate for the difference between the production rate and the demand. However, the production overshoot increases with the increase of the gain leaving the trade-off decision for the supervisory controller to decide how to balance between supplying required capacity while maintaining an acceptable level of amplification or production cost.

Finally, it is obvious that the offset error with the capacity/WIP MPC policy is less than that with the capacity based policy. This is due to the contribution of the WIP controller to increase the production rate. The significant thing herc when comparing both policies is that with capacity/WIP the overshooting is much less than that with capacity based while the level of responsiveness is almost the same (same rise time and even better settling time for the capacity/WIP MPC policy). This can lead to the conclusion that contrary to the case of inventory based policies, the capacity/WIP-based policy is always superior over the capacity-based MPC policy.

\subsubsection{The effect of the WIP controller gain}

In this section we examine the effect of the WIP controller gain on the two general MPC policies, the inventory-based MPC and the capacity based policy. The same approach of varying the value of the WIP controller gain and testing the response of both policies against a step change in demand at different gain values is implemented. Figures 6 and 7 show the results for both systems. Analysing the results of both MPC systems reveals the following points.

Figure 6 Response of the inventory/WIP-based MPC configuration for a step change in demand with different inventory gain values $\left(T_{\mathrm{LT}}=5\right.$ days, $T_{\mathrm{SR}}=3$ days and $\left.G_{1}=1\right)$ (see online version for colours)

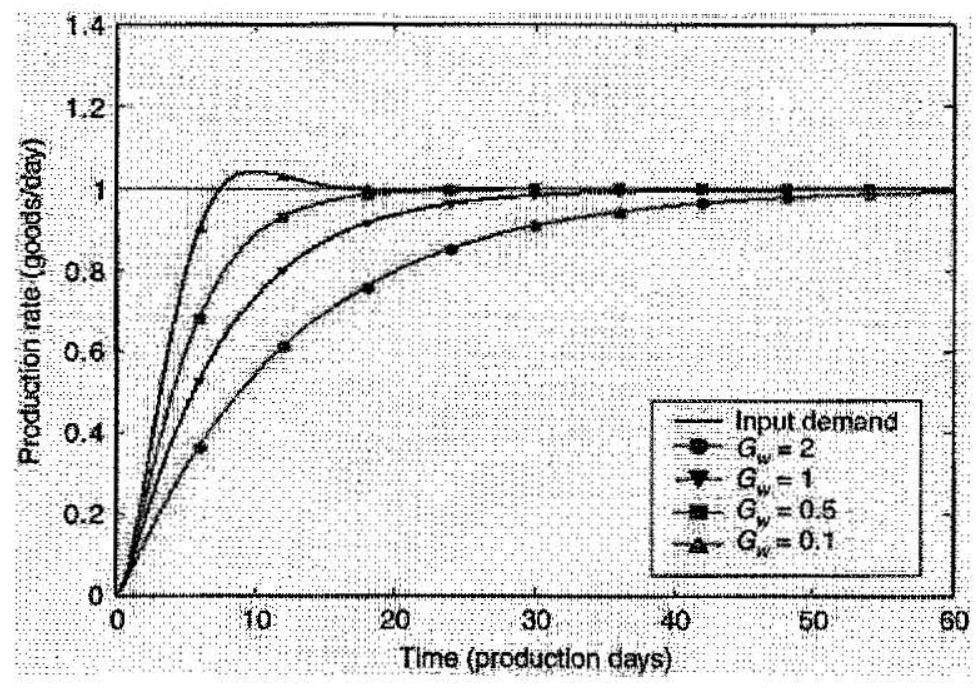


Figure 7 Response of the capacity/WIP-based MPC configuration for a step change in demand with diferent capacity gain values $\left(T_{1, T}=5\right.$ days, $T_{\mathrm{D}}=3$ days and $\left.\mathrm{G}_{C}=1\right)$ (see online version for colours)

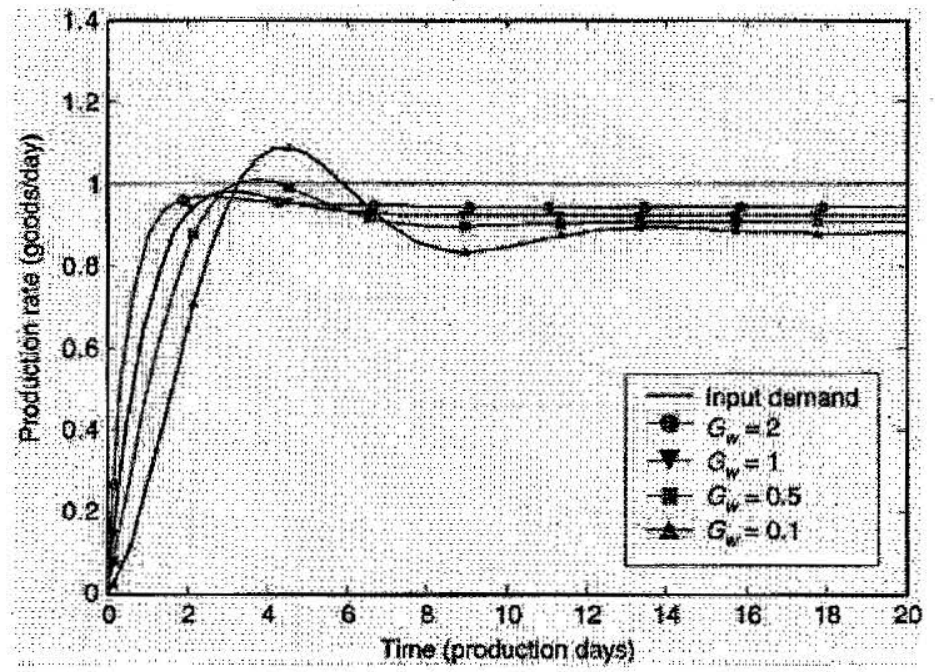

Firstly, the damping effect of the WIP controller gain is very clear since production overshooting decreases as the value of that gain increases in both MPC policies. This can be also explained since WIP will keep production rate in a good level while adjusting the capacity rate (in case of capacity based MPC) or the input rate (in case of the inventorybased MPC). From a dynamic stand point this can be explained by examining the damping ratio in the characteristic equation of the two MPC models. As shown in Equation (10) for the capacity/WIP MPC system and Equation (11) for inventory/WIP MPC system that the major controllable factor that can increase the damping ratio $\zeta$, and thus decreasing the overshooting, is the WIP control gain $G_{w}$ Other controllers' gains can share in this through affecting the natural frequency, $\omega_{n}$, of the manufacturing systcm. However they are assumed to be fixed in order to highlight the effect of the WIP controller gain.

$$
\xi=\frac{1}{2 \omega_{n}}\left(\frac{1}{T_{\mathrm{LI}}}+\frac{1}{T_{D}}+G_{w}\right)
$$

where

$$
\begin{aligned}
& \omega_{n}=\sqrt{\frac{G_{\mathrm{W}} T_{\mathrm{LT}}+G_{C}+1}{T_{\mathrm{LT}} T_{D}}} \\
& \xi=\frac{1}{2 \omega_{n}}\left(\frac{1}{T_{\mathrm{LT}}}+\frac{1}{T_{\mathrm{SR}}}+G_{W}\right)
\end{aligned}
$$

where

$$
\omega_{n}=\sqrt{\frac{G_{\mathrm{t}}}{T_{\mathrm{LT}}}}
$$


Sccondly, the reduction of the production overshooting in inventory/WIP MPC system was on the expense of the rise time (i.e. system's responsivcness) while it was the opposite in the case of capacity/WIP MPC system. This can be explained through examining the rise time Equation (12) and realising that the WIP control gain $\left(G_{\mathrm{w}}\right)$ positively affects the natural frequency of the capacity/WIP MPC system while it has no effect on the natural frequency of the inventory/WIP MPC system. This is why, in case of capacity/WIP MPC systems, when $\left(G_{w}\right)$ increases; it damps the production overshooting and at the same time increases the system's natural frequency which in turns increases its responsiveness.

$$
t_{r, 10,90 \cong}=\frac{0.8+2.5 \xi}{\omega_{n}} \quad 0 \leq \xi \leq 1
$$

Finally, observing the settling time for both MPC systems again emphasises the fact that generally capacity-based MPC systems are much more responsive than inventory-based MPC systems.

\subsection{Stability analysis}

One of the advantages of dynamic modelling using transfer functions is the ability to conduct a stability test for the system. It is essential to know when the MPC system is stable and when it is unstable. It is particularly important to understand system instability, as in such cases the system response to any change in input will result in uncontrollable oscillations of increasing amplitude and apparent chaos ensuing in manufacturing system. In our analysis we will aim to determine the limiting conditions for stability in terms of the different control gains values.

The gencral Routh-Hurwitz method (Nise, 2000) is used to investigate stability limits. The method for sccond-order systems is shown in Table 1 where, coefficients $a_{0}$ to $a_{2}$ refer to the coefficients of the denominator in Equations (2)-(5) according to which MPC configuration tested. Based on the method, the second column of Table 1 should always be positive. It is important here to remember that the manufacturing system's time variables $\left(T_{\mathrm{LT}}, T_{\mathrm{SR}}\right.$ and $\left.T_{\mathrm{D}}\right)$ are always positive.

Table 1 The general Routh-Hurwitz method for the second-order systems

\begin{tabular}{ccc}
\hline$s^{2}$ & $a_{2}$ & $a_{0}$ \\
$s^{2}$ & $a_{1}$ & 0 \\
$S^{0}$ & $\frac{\left(a_{0} * a_{1}\right)-\left(a_{2} * 0\right)}{a_{1}}=a_{0}$ & 0 \\
\hline
\end{tabular}

Results of applying the Routh-Hurwitz method for the different MPC configurations are displayed in Table 2. The analysis of the results is explained in Table 3. It should be noted that these stability limits are within the assumptions stated earlier in Section 3 for the system time variables. 
Table 2 The Routh-Hurwitz. Method established for the different MPC configurations

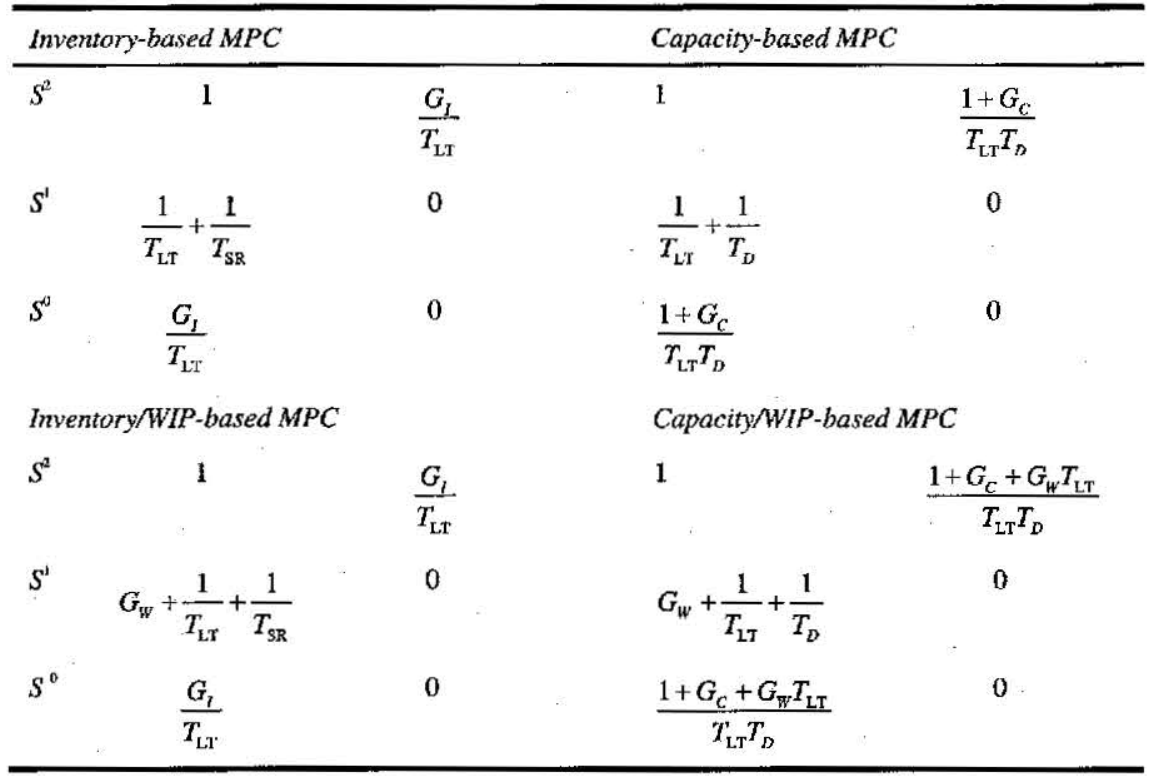

Table 3 Analysis of the stability limits of the different MPC configurations

\begin{tabular}{lll}
\hline MPC configuration & Stability limits & \multicolumn{1}{c}{ Description } \\
\hline Inventory-based & $G_{1}>0$ & $\begin{array}{l}\text { Practically, the MPC system cannot } \\
\text { reduce the input rate through this } \\
\text { gain. }\end{array}$ \\
Capacity-based & $G_{C}>-1$ & $\begin{array}{l}\text { In case of down scaling capacity rate, } \\
\text { the value of capacity rate reduction } \\
\text { must be less than -1. }\end{array}$ \\
Inventory/WIP-based & $G_{1}>0$ & $\begin{array}{l}\text { The WIP controller gain reduction } \\
\text { should be limited to the given } \\
\text { incquality. The limitation can } \\
\text { be altered by changing the lead } \\
\text { time and/or the shipment } \\
\text { rate. }\end{array}$ \\
Capacity/WIP-based & $G_{\mathrm{W}}>-\left(\frac{1}{T_{\mathrm{LT}}}+\frac{1}{T_{\mathrm{SR}}}\right)$ & $\begin{array}{l}\text { There is a limit to how much the } \\
\text { system can reduce its capacity } \\
\text { rate based on the lead time and delay } \\
\text { time. This limit's value can be } \\
\text { decreased or increased using the } \\
\text { WIP control gain. The WIP controller } \\
\text { gain is subject to the same analysis } \\
\text { as in the inventory based } \\
\text { policy. }\end{array}$ \\
\hline$G_{\mathrm{F}}>-\left(\frac{T_{\mathrm{LT}} T_{D}}{G_{\mathrm{H}} T_{\mathrm{LT}}+1}\right)$
\end{tabular}




\section{Evaluation of model performance}

Evaluating the dynamic performance of the developed reconfigurable MPC model leads to a number of important points in realising reconfigurability in manufacturing systems.

Any MPC policy nceds a reaction time to respond to market changes. This time can be controlled through designing the suitable MPC systcms controllers' gains.

Setting the optimal MPC system controllers' gains values involves multiple trade-off decisions. Results showed that achieving quick reaction time in both inventory-based MPC systems via increasing the value of the inventory controller gain was always on the expense of production cost. In addition, reducing the production offset problem in both capacity-based MPC systcms through increasing the capacity controller gain was also on the expense of production overshooting. Finally the value of the WIP controller gain in inventory/WIP MPC system should be balanced with its effect of decreasing the responsiveness of the system.

Inventory-based MPC systems (with the previous stated assumptions) does not suffer from production offset when reacting to demand changes like capacity-based MPC systems. This means that if high service level is the competitive component in RMS, it is better to adopt an inventory based MPC policy to hedge against demand changes.

Capacity-based MPC systems showed more responsiveness to demand changes than inventory-based MPC systems. This observation leads us to say that in RMS when delivery performance is an essential competitive component, it is better to adopt capacity-based MPC policies.

Accounting for WIP in reconfigurable MPC systems is important. In inventory-based MPC system the damping effect of the WIP controller gain was significant and helped in decreasing production overshoot. However, as mentioned earlier this was on the expense of system's responsiveness. As for capacity-bascd MPC system, the role of WIP controller gain is more significant. It does not only damp production overshooting, but also increases the system's responsiveness.

Based on the previous result on can say that capacity/WIP-based MPC system is the best alternative if the higher management level would like to adopt a capacity-based MPC policy.

All MPC policics (based on the stated time variables assumptions) showed a good level of stability in terms of increasing any controllers' gain. However, caution should be taken when reducing the values of these gains as not to go over the stability limit of these systems. The stability limits of the capacity-based MPC systems can be altered through manipulating the value of the WIP gain controller.

The significance of the results presented in the previous analysis is mainly in demonstrating different dynamic characteristics for the various policies that the developed reconfigurable MPC system can adopt. This demonstration will aid the MPC decision logic unit to assess the anticipated performance of the system under different external or internal disturbances. Such analysis is. an essential step in the optimal design of the different controllers involved in the MPC system. From a practical stand point, the proposed reconfigurable MPC system acts as a decision support system at the tactical level of the manufacturing enterprise to aid in taking decisions concerning capacity, inventory and WIP levels that will align the higher market stratcgy with the operational level implementation. Such alliance is essential to achieve responsiveness and cost effectiveness which are the major drivers of RMS. 


\section{Conclusion and future work}

The concept of RMS from a manufacturing planning and control perspective was discussed where reconfigurability of MPC system can be defined as the ability to adopt different policies based on the current market strategy. A dynamic model for reconfigurable MPC system was presented where different MPC policies can bc adopted by reconfiguring the system and where a supervisory controller is responsible to handle this reconfiguration process based on current market strategy and trade-off decisions between competing performance measures. The adequacy of the model and the effect of the diffcrent controllers' gains have been demonstrated by simulating the response of different MPC system configuration. Analysis of the results highlighted the competitive advantages and limitations of the two main MPC policies, inventory-based and capacity-based MPC systems. The stability of the MPC system was investigated and it was realised that special attention should be paid to when down-scaling capacity rate in capacity-based MPC systems or decreasing the input rate in inventory-based MPC systems so as not to exceed stability limits. Finally, we emphasise that a proper understanding of the dynamic effects of MPC system's parameters helps in the optimal selection of the best MPC policy and in turn realising agility in RMS.

In the future, we shall study the detailed design of the supervisory controller responsible for managing the reconfigurable MPC system with its different control algorithms.

\section{References}

Asl, R. and Ulsoy, A. (2002) 'Capacity management via feedback control in reconfigurablc manufacturing systems', Proceedings of Japan/USA Symposium on Flexible Manufacturing Automation, Hiroshima, Japan.

Baganha, M. and Cohen, M. (1998) 'The stabilizing effect of inventory in supply chain', Journal of Operation Research, Vol. 46, No. 3, pp.572-583.

Baines, T. and Harrison, D. (1999) 'An opportunity for system dynamics in manufacturing system modelling', Journal of Production Planning and Control, Vol. 10, No. 6, pp.542-552.

Chan, J. and Burns, N. (2002) 'Benchmarking manufacturing planning and control MPC systems: an empirical study of Hong Kong supply chains', Benchmarking: An International Journal, Vol. 9, No. 3, pp.256-277.

Chryssolouris, G., Giannelos, N., Papakostas, N. and Mourtzis, D. (2004) 'Chaos theory in production scheduling', Annals of CIRP, Vol. 53, No. 1, pp.3-6.

Coyle, R. (1996) System Dynamics Modeling a Practical Approach, London: Chapman \& Hall.

Deif, A. and ElMaraghy, W. (2006) 'A control approach to explore capacity scalability scheduling in recontigurable manufacturing systems', Journal of Manufacturing Systems, Vol. 25/1, pp.12-24.

Dejonckheere, J., Diseny, S., Lambrecht, M. and Towill, D. (2003) 'Dynamics of aggregate planning', Journal of Production and Planning Control, Vol. 14, No. 6, pp.497-516.

Deziel, D. and Eilon, S. (1967) 'A linear production-inventory control rulc', The Production Engineer, Vol. 43,pp.93-104.

Diseny, S. and Towill, D. (2002) 'A discrete transfer function model to determine the dynamic stability of a vendor managed inventory in supply chain', Intemational Journal of Production Research, Vol. 40, No. 1,pp.179-204.

Diseny, S. and Towill, D. (2005) 'Eliminating drift in inventory and order based production control systems', International Journal of Production Economics, Vols. 93-94, pp.331-344. 
Duffie, N. and Falu, I. (2002) 'Control-theoretic analysis of a closed loop PPC system', Annals of CIRP, Vol. 52, No. 1, pp.379-382.

Duffie, N., Prabhu, V. and Kaltjob, P. (2002) 'Closed-loop rcal-time cooperative decision-making dynamics in heterarchical manufacturing systems', Journal of Manufacturing Systems, Vol. 21, No. 6, pp.409-418.

ElMaraghy, H. (2003) 'Fundamentals of flexible manufacturing systems', Class Notes, University of Windsor.

Fong, N., Sturges, R. and Schewchuk, J. (2004) 'Understanding system dynamics via transfer function in modelling production control systems', Proceedings of FAIM-Toronto, pp.1033-1042.

Forrester, J. (1961) Industrial Dynamics, Cambridge, USA: MIT Press.

Helo, P. (2000) 'Dynamic modelling of surge effect and capacity limitation in supply chains', International Journal of Production Research, Vol. 38, No. 17, pp.4521-4533.

Hopp, J. and Spearman, L. (1996) Factory Physics - Foundations of Manufacturing Management, Boston: Irwin McGraw-Hill.

Hoyt, J. (1980) 'Determining lead time for manufactured parts in a job shop', in J.J. Pennsanken (Ed). Computers in Manufacturing, pp.1-12.

John, S., Towill, D.R. and Naim, M. (1994) 'Dynamic analysis of a WIP compensated support system', International Journal of Manufacturing System Design, Vol. 1, pp.283-297.

Kim, J-H. and Duffie, N. (2004) 'Backlog control design for a closed loop PPC system', Annals of CIRP, Vol. 54, No. 1, pp.456-459.

Kim, J-H. and Duffie, N. (2005) 'Design and analysis of closed loop capacity control for a multi-workstation production system', Annals of CIRP, Vol. 55, No. 1, pp.470-473.

Koren, Y., Heisel, U., Jovane, F. and Moriwaki, T. (1999) 'Reconfigurable manufacturing system', Annals of CIRP, Vol. 48, Keynote paper.

Lodding, H., Yu, K. and Wiendahl, H-P. (2003) 'Decentralized WIP-oriented manufacturing control (DEWIP)', Journal of Production Planning and Control, Vol. 14, No. 1, pp.42-54.

Mchrabi, M., Ulsoy, G. and Koren, Y. (2000) 'Reconfigurable manufacturing systems: key to future manufacturing', Journal of Intelligent Manufacturing, Vol. 11, pp.403-419.

Nise, N. (2000) Control Systems Engineering, NY: John Wiley \& Sons.

Nyhuis, P. (1994) 'Logistic operating curves - a comprehensive method for rating logistic potentials', EURO XIII/OR36, University of Strathclyde Glasgow, pp.19-22.

Pritschow, G. and Wiendahl, H.P. (1995) 'Management and control of complexity in manufacturing', Annals of the CIRP, Vol. 44, No. 1, pp.421-423.

Radons, G. and Neugebaucr, R. (2005) Nonlinear Dynamics of Production Systems, VCH: Willy.

Ratering, A. and Duffie, N. (2003) 'Design and analysis of closed-loop single-workstation PPC system', Annals of CIRP, Vol. 52, No. 1, pp.375-379.

Reid, R. and Koljonen, E. (1999) 'Validating a manufacturing paradigm: a system dynamics modelling approach', Proceedings of the 1999 Winter Simulation Conference, pp.759-765.

Schmitz, J., van Beek, D. and Rooda, J. (2002) 'Chaos in discrete production systems', Journal of Manufacturing Systems, Vol. 21, No. 3, pp.236-246.

Scholz-Reiter, B. and Schmieder, F. (2002) 'Modelling and control of production systems based on nonlinear dynamics theory', Annals of CIRP, Vol. 51, No. 1, pp.375-379.

Simon, H. (1952) 'On the application of servomechanism theory in the study of production control', Econometrica, Vol. 20, No. 2, pp.247-268.

Sterman, J.D. (2000) Business Dynamics - Systems Thinking and Modeling for a Complex World, NY: McGraw-Hill.

Towill, D. (1982) 'Dynamic analysis of an inventory control and order-based production control system', International Journal of Production Research, Vol. 20, pp.671-687. 
Towill, D., Evans, G. and Cheema, P. (1997) 'Analysis of an adaptive reasonable inventory control system', Journal of Production Planning and Control, Yol. 8, No. 6, pp.545-557.

Towill, D.R. and Del Vecchio, A. (1994) 'The application of filter theory to the study of the supply chain dynamics', Joumal of Production Planning and Control, Vol. 15, No. 1, pp.82-96.

Vassian, H. (1955) 'Application of discrete variable servo theory to inventory control', Journal of Operation Research Society of America, Vol. 3, No. 3, pp.272-282.

Venkatesh, K., Zhou, M., Kaighobadi, M. and Caudill, R. (1996) 'A petri-net approach to investigate push and pull paradigm in flexible factory automated systems', International Journal of Production Research, Vol. 34, No. 3, pp.595-620.

Wacker, J. and Hanson, M. (1997) 'Some practical advice for manufacturing managers: empirical results from the global manufacturing research group', Production and Inventory Management Joumal, Vol. 38, No. 3, pp.64-71.

Wiendahl, H.P. (1995) Load Oriented Manufacturing Control, Hanover, NH: Springer-Verlag.

Wiendahl, H.P. and Breithaupt, J. (1999) 'Modeling and controling of dynamics of production system', Joumal of Production Planning and Control, Vol. 10, No. 4, pp.389-401.

Wiendahl, H.P. and Breithaupt, J. (2000) 'Automatic production control applying control theory', International Journal of Production Economics, Vol. 63, pp.33-46.

Wiendahl, H.P. and Worbs, J. (2003) 'Simulated based analysis of complex production systerns with methods of nonlinear dynamics', Joumal of Material Processing Technology, Vol. 139. pp.28-34.

Wikner, J., Towill, D. and Naim, M. (1991) 'Smoothing supply chain dynamics', International Journal of Production Economics, Vol. 22, pp.231-248. 